\title{
Aonde chega o Judiciário? Uma avaliação da expansão da Justiça do Trabalho no Brasil (2003-2010)
}

\author{
Eduardo Matos Oliveira ${ }^{1}$
}

\begin{abstract}
Quais fatores determinam a criação das varas da Justiça do Trabalho no Brasil? Esse é o problema do artigo. De acordo com os critérios constitucionais, a população e a demanda judicial deveriam nortear a criação das varas judiciais. Porém, a literatura de acesso à justiça indica que talvez o desenvolvimento socioeconômico seja o fator determinante para o seu surgimento. Considerando que a expansão da Justiça do Trabalho ocorreu sobretudo, nas últimas décadas, foi possível realizar um modelo de regressão logística para testar o efeito de variáveis geográficas, socioeconômicas e demográficas na criação das unidades. Os resultados demonstraram que o impacto da população economicamente ativa e da proporção de pessoas cursando o ensino superior no município foram relevantes. Os municípios mais distantes das varas do trabalho já existentes e com menos unidades em funcionamento também foram mais contemplados na expansão da Justiça do Trabalho.

Palavras-chave: Justiça do Trabalho; judiciário; acesso à justiça; varas judiciais; municípios
\end{abstract}

\section{Introdução}

Após três décadas de expansão ininterrupta na Justiça do Trabalho no Brasil, uma pergunta permanece: quais fatores determinaram a criação das varas? De acordo com os critérios constitucionais, a população e a demanda judicial deveriam nortear a criação das novas unidades, porém, a literatura de acesso à justiça indica que talvez o desenvolvimento socioeconômico seja o fator determinante para o seu surgimento.

Naturalmente, o debate não é restrito à esfera trabalhista. Pesquisas empíricas interessadas na prestação do serviço jurisdicional revelaram uma forte correlação entre a presença da Justiça Estadual e o Índice de Desenvolvimento Humano no país. Ou seja, as comarcas estaduais, bem como o maior volume processual, estão concentradas nos municípios e regiões com maior desenvolvimento socioeconômico (ver Sadek, 2001;

\footnotetext{
1 Universidade Federal de Pernambuco, Recife (PE), Brasil. E-mail: <eduardo.matos.oliveira@gmail.com>. Orcid: <https://orcid.org/0000-0002-5897-5201>.

${ }^{2}$ Agradeço os comentários e sugestões de Leon Victor Queiroz, Mariana Batista, Marcelo de A. Medeiros, Cinthia Campos, Eugênia Barza, Marcos C. Lima, Hugo C. Melo, Mariana Cockles, Lucas Gelape, João Cumarú e aos pareceristas anônimos da revista Opinião Pública.
} 
Marona, 2013; Avritzer, Marona e Gomes, 2014). Certamente, existem muitos obstáculos ao acesso à justiça além da presença física do órgão judicial, no entanto, esse é o primeiro requisito para avaliar a atividade forense em relação ao cidadão comum.

Na literatura empírica sobre o acesso à justiça, embora o debate tenha abarcado órgãos relevantes do Estado como a Defensoria Pública e a Justiça Estadual, pouco se discutiu sobre a Justiça do Trabalho. É notória a importância da justiça especializada em questões trabalhistas, principalmente em municípios com maior população, a fim de garantir o cumprimento da legislação. Portanto, pretendemos suprir essa lacuna e expandir os estudos sobre o acesso à justiça para analisar a Justiça do Trabalho. A questão que se coloca é se a criação das varas trabalhistas acompanhou o recorte geográfico desigual da Justiça Estadual ou se apresenta uma realocação geográfica mais próxima dos parâmetros estabelecidos na legislação.

Em outras palavras, a pesquisa busca desvendar quais condições determinaram o recebimento de uma vara do trabalho nos municípios brasileiros. Considerando os critérios constitucionais, espera-se que a população economicamente ativa (PEA) seja a variável com maior potencial explicativo. Contudo, a literatura sugere que a renda per capita e o nível de escolaridade desempenhem um papel relevante no processo. Também foi inserida na análise a distância do município para a vara do trabalho mais próxima e a estrutura judicial presente na localidade, medida através do número de varas do trabalho em funcionamento. A distância para a capital do estado da federação e o percentual de ocupados em cada setor da economia também estão presentes no modelo.

Os estudos realizados anteriormente com a Justiça Estadual utilizaram as técnicas de descrição e correlação, já que as varas estaduais foram criadas muitas décadas atrás. Por outro lado, a Justiça do Trabalho se expandiu recentemente, em especial após a Constituição de 1988, portanto foi possível realizar um modelo estatístico a fim de verificar o impacto das variáveis explicativas no recebimento das varas do trabalho. Considerando que a Lei n $10.770 / 2003$ criou mais de 200 varas distribuídas em todos os Tribunais Regionais do Trabalho, foi possível desenhar a pesquisa para mensurar as variáveis explicativas no período imediatamente anterior à criação da lei.

Portanto, a análise foi feita entre 2003 e 2010, em virtude do fato de que as unidades judiciárias da Justiça do Trabalho criadas durante essa década, por meio de legislação, foram todas concentradas na Lei $n^{\circ} 10.770 / 2003$. A técnica de análise será a regressão logística, visto que a variável dependente corresponde ao recebimento pelo município de uma vara do trabalho, ou seja, é uma variável categórica binária. Também será feita uma análise espacial dos municípios onde foram criadas varas trabalhistas. Serão apresentados os mapas com as localidades que receberam unidades em contraste com o Índice de Desenvolvimento Humano Municipal, a fim de verificar se é possível encontrar uma relação entre os dois fatores.

Para verificar a relação entre a movimentação do volume processual e a criação de varas do trabalho com a Lei $n^{\circ} 10.770 / 2003$, foram realizadas correlações entre os 
dois fatores. Considerando que os dados para a década de 2000-2010 estão disponíveis apenas de forma agregada por Tribunais Regionais do Trabalho, as correlações foram feitas tendo o tribunal como unidade de análise. Por fim, com o objetivo de testar se as regras estabelecidas para a criação de novas unidades judiciárias estão sendo respeitadas, serão analisadas as varas criadas entre 2010 e 2015 de acordo com os critérios determinados pela Resolução 63 de 2010 do Conselho Superior da Justiça do Trabalho.

Através da análise dos resultados, observou-se que o impacto da população economicamente ativa foi importante para explicar o recebimento das varas do trabalho entre 2003 e 2010. A renda per capita não apresentou o resultado esperado a partir dos estudos da Justiça Estadual, ao passo que o indicador educacional foi significativo estatisticamente. Os municípios mais distantes das varas do trabalho já existentes e com menos unidades em funcionamento também foram mais contemplados na expansão da Justiça do Trabalho. Em termos de variáveis econômicas, a proporção de indivíduos ocupados no setor de comércio foi o fator mais relevante.

Na primeira seção do artigo, serão discutidos os principais debates recentes do acesso à justiça. Em seguida, será apresentado o processo de crescimento e institucionalização da Justiça do Trabalho no Brasil, assim como o procedimento para criação das varas do trabalho. Na terceira parte, serão detalhados os aspectos metodológicos da pesquisa. Na apresentação dos resultados, serão analisados os principais fatores que determinaram o recebimento das unidades da Justiça do Trabalho entre 2003 e 2010, a correlação entre movimentação processual e criação das varas na Lei no 10.770/2003 por Tribunal Regional do Trabalho e a aplicação dos critérios do Conselho Superior da Justiça do Trabalho nas varas criadas entre 2010 e 2015.

\section{Os debates do acesso à justiça}

O acesso à justiça é a garantia mais básica do Estado democrático de direito, sem isso nenhum outro direito pode ser concretizado. Segundo coloca Sadek (2001, p. 7), "os direitos são letra morta na ausência de instâncias que garantam seu cumprimento". É notório que a grande expansão do Judiciário durante o século XX envolveu, sobretudo, a judicialização da política e o Judiciário enquanto poder do Estado (ver Tate e Vallinder, 1995; Ferejohn, 2002; Vianna, 1999; Sadek, 2004; Carvalho, 2007). Porém, o crescimento e ampliação do Judiciário ocorreram não só pela via constitucional, mas também através da justiça comum (Arantes, 2014, p. 51).

Em termos de pesquisa comparada entre países sobre o acesso à justiça, destaca-se a importância do relatório do Florence Project (Cappelletti e Garth, 1988). A pesquisa apresenta um enfoque institucional a respeito da organização do Judiciário e da legislação, trazendo uma abordagem baseada em três ondas de acesso à justiça. Primeiramente, abordam-se as barreiras econômicas, que representam o que os autores 
convencionaram chamar de primeira onda. Em seguida, tratou-se dos problemas da representação dos interesses difusos e coletivos, que constituíram a segunda onda de acesso à justiça. Por fim, na terceira onda, inicia-se a discussão sobre formas alternativas de resolução de conflitos e simplificação dos procedimentos (Cappelletti e Garth, 1988).

Ressalta-se também a relevância das contribuições de Kim Economides, que participou do Florence Project (Cappelletti e Garth, 1988) e posteriormente propôs o debate a respeito de uma quarta onda de acesso à justiça. Para o autor, a quarta onda "expõe as dimensões ética e política da administração da justiça e, assim, indica importantes e novos desafios tanto para a responsabilidade profissional como para o ensino jurídico" (Economides, 1999, p. 72), ou seja, o foco é o acesso à justiça por parte dos operadores do direito. A ideia é verificar o acesso dos cidadãos ao ensino do direito e às profissões jurídicas, além de questões referentes à igualdade de oportunidades e ao exercício do profissionalismo humanitário (Economides, 1999, p. 74).

Economides, em parceria com Blacksell e Watkins, desenvolveu também um projeto envolvendo aspectos territoriais do acesso à justiça. A pesquisa analisou a atuação de advogados em três distritos rurais do Reino Unido com base em entrevistas e procurou entender, por exemplo, a diferença entre os cálculos relacionados à busca por uma solução judicial para aqueles que vivem no interior (Blacksell, Economides e Watkins, 1991, p. 148). Em face de problemas como a concentração de advogados em áreas urbanas, os autores fazem uma análise voltada a oferecer soluções referentes à política pública de acesso à justiça nas áreas rurais.

Na Europa e nos Estados Unidos, a expansão dos serviços judiciais, inclusive a criação dos diversos programas de acesso à justiça descritos nas ondas, esteve diretamente ligada ao surgimento e à crise do Estado de bem-estar social, conforme colocam Santos, Marques e Pedroso (1996). Com o desenvolvimento do welfare State, novas formas de litígios surgiram em campos que não existiam antes, tal como a seguridade social, novas fronteiras do direito do trabalho e direito administrativo. Nas décadas de 1980 e 1990, com o retorno da lógica liberal na política econômica, mesmo existindo o crescimento da demanda nesses países, houve uma limitação na concessão da justiça gratuita e nos serviços de apoio jurídico fornecidos pelo Estado. Inclusive, segundo Pedroso, Trincão e Dias (2003, p. 84), nos anos 1990, os critérios de elegibilidade para o acesso aos serviços judiciais na Europa retomaram os esquemas caritativos anteriores à Segunda Guerra Mundial.

No Brasil, contudo, a dinâmica do acesso à justiça foi diferente do processo europeu e norte-americano, uma vez que o foco não era a "expansão do welfare State e a necessidade de se tornarem efetivos os novos direitos conquistados principalmente a partir dos anos 1960 pelas minorias étnicas e sexuais, mas sim a própria necessidade de se expandirem para o conjunto da população direitos básicos" (Junqueira, 1996, p. 1). Consoante destaca Junqueira (1996), o caso brasileiro não segue a lógica das três ondas 
de acesso à justiça descritas por Cappelletti e Garth (1988). Embora existam pesquisas brasileiras nos anos 1980 a respeito dos direitos coletivos, a motivação não era a crise do Estado de bem-estar social, mas a exclusão de grande parte da população dos direitos sociais básicos (Junqueira, 1996, p. 2).

Inclusive, enquanto na Europa a criação dos tribunais especializados, em geral, inseriu-se na terceira onda de acesso à justiça (Cappelletti e Garth, 1988, p. 33), no Brasil, a origem da Justiça do Trabalho foi resultado de um processo político distinto. A conjuntura dos anos 1930 durante o governo Vargas formou um forte consenso antiliberal, possibilitando o surgimento do projeto de uma Justiça do Trabalho federalizada. A principal força política aglutinadora foram os corporativistas, que também contaram com o apoio dos socialistas e católicos que, apesar dos interesses distintos, apoiavam uma intervenção do Estado na economia e nas relações de trabalho (Morel e Pessanha, 2007, p. 89).

As pesquisas brasileiras sobre o acesso à justiça começaram a florescer na década de 1980. Cabe ressaltar a relevância do trabalho de Falcão (1981), que analisou a inadimplência coletiva no sistema financeiro de habitação nos anos 1980 e a representação coletiva através dos sindicatos, para concluir que o Judiciário brasileiro na época não era a principal instância de resolução de conflitos coletivos na sociedade. Ele acrescenta que "esta recusa ou encolhimento do Judiciário não faz com que esses conflitos desapareçam ou percam intensidade. São apenas remetidos para outras arenas de resolução" (Falcão, 1981, p. 17).

Outra referência importante foi a pesquisa "Sua Excelência, o comissário" realizada por Oliveira (2004) e publicada também originalmente nos anos 1980. O estudo destaca a execução de práticas tipicamente judiciais realizadas pela polícia na resolução de casos considerados menores. O autor descreve como a autoridade policial resolve os conflitos dos indivíduos de baixa renda sem encaminhar o processo para o juiz e o Ministério Público, especialmente questões relacionadas a ofensas morais, agressões e desordem (Oliveira, 2004). Junqueira (1996, p. 5) acrescenta que, durante os anos 1980, no Rio de Janeiro, destacou-se a produção de pesquisas do Departamento de Direito da PUC-Rio, iniciando-se com um estudo sobre o relacionamento entre as associações de moradores e o Poder Judiciário em 1984.

Santos (1999, p. 147), que influenciou a geração de pesquisadores brasileiros interessados no tema, aponta que as barreiras sociais e culturais também são importantes para o debate do acesso à justiça. Por exemplo, há questões sociais e culturais sutis que representam barreiras simbólicas. Sadek (2014, p. 58) cita "o linguajar hermético por parte dos operadores do direito, procedimentos complicados, o excesso de formalismo e os ambientes que provocam intimidação, como a suntuosidade dos tribunais". A questão do vocabulário próprio utilizado nas peças jurídicas é referida por Warat (1994) como uma forma de transformar sujeitos sociais em objetos de poder. Naturalmente, o uso de palavras em estilo rococó acarreta a inacessibilidade do conteúdo 
por parte de pessoas que não pertencem ao meio jurídico, chegando ao absurdo de um reclamante não ser capaz de entender a sentença do próprio processo sem a ajuda de um advogado.

Recentemente, na literatura sobre acesso à justiça no Brasil, ganharam destaque as preocupações envolvendo a distribuição territorial dos serviços judiciais no país. Os estudos focam, sobretudo, na relação entre a expansão dos órgãos do Judiciário e os indicadores de desenvolvimento econômico e social, em especial, o Índice de Desenvolvimento Humano Municipal. Porém, há também uma diversidade de abordagens e enfoques no campo. Sinhoretto (2011), por exemplo, realizou uma etnografia em três Centros de Integração e Cidadania da periferia de São Paulo e relata o distanciamento do povo em relação ao sistema de justiça. A autora propõe uma inversão na forma de colocar o problema do acesso à justiça: é a justiça que vai em direção ao povo, não o contrário.

Em termos de estudos quantitativos, ao observar a movimentação processual no país, Sadek (2001) faz uma correlação entre o Índice de Desenvolvimento Humano (IDH) das regiões do Brasil e o número de processos que entraram e saíram do Judiciário. 0 Sudeste recebe 12 vezes mais processos que o Nordeste, mesmo que a diferença populacional seja menor que o dobro. Ainda mais inquietante é o fato de a região Sul receber quase cinco vezes mais processos que o Nordeste, apesar de ter uma população significativamente menor. Durante o período da pesquisa (1990-1998), o Sudeste apresentou uma média de 1 processo para 20 habitantes; no Sul a média foi de 1 para 23; no Centro-Oeste, de 1 para 31; no Nordeste, de 1 para 137, e no Norte, de 1 para 80.

Uma das questões que surgem a partir dos dados trazidos por Sadek (2001) é saber se os indivíduos nas regiões mais pobres, em especial o Norte e o Nordeste, procuram menos o Judiciário por não conhecerem seus direitos, ou se, pelo fato de essas regiões serem mais vulneráveis, há uma menor presença dos órgãos do sistema de justiça e, consequentemente, um menor número de processos. Possivelmente, os dois fatores atuam de forma combinada.

Outra contribuição de grande importância para os estudos de acesso à justiça foi trazida por Marona (2013) ao trabalhar o enfoque cartográfico, uma vez que a distribuição geográfica dos órgãos do Judiciário é de grande importância, o que justifica uma análise empírica sobre o acesso à justiça. A pesquisa analisa a distribuição desigual do Judiciário no território brasileiro. Ela faz uma reconstrução dos mapas do sistema formal de justiça a partir de uma categoria de desigualdade social, que é o Índice de Desenvolvimento Humano. O levantamento foi feito em cinco estados da federação: Minas Gerais, Rio Grande do Sul, Goiás, Pará e Pernambuco, a fim de verificar se a ausência de varas da Justiça Estadual está ligada ao desenvolvimento socioeconômico, medido através do IDH (Marona, 2013, p. 126). 
Os resultados mostram que nos estados de Minas Gerais, Rio Grande do Sul e Goiás há uma forte correlação entre um alto IDH e a presença de uma vara da justiça. Em Pernambuco e no Pará não foi possível verificar se há correlação, porque existem mais municípios que são sede de comarca, em termos relativos. Porém, isso não significa que esses dois estados tenham uma distribuição equitativa dos órgãos judiciais, visto que apenas na capital há comarca com maior nível de complexidade e especialização (Marona, 2013, p. 153).

Em 2014, foi lançada a Cartografia da Justiça no Brasil (Avritzer, Marona e Gomes, 2014), que traz uma expansão da pesquisa mencionada acima. Os autores fizeram o levantamento de dados de mais cinco estados da federação: Santa Catarina, São Paulo, Rondônia, Maranhão e Rio de Janeiro, que se juntou às análises dos mapas de Pernambuco, Pará, Goiás, Rio Grande do Sul e Minas Gerais. Os autores concluem que, em geral, há coincidência entre os altos níveis de desenvolvimento humano e a presença da justiça.

Na cartografia, os autores também abordam o tema da presença da Defensoria Pública Estadual nas comarcas brasileiras. Eles utilizam os dados do projeto "Mapa da Defensoria Pública no Brasil", que foi conduzido pelo Instituto de Pesquisa Econômica Aplicada (Ipea) em parceria com a Associação Nacional dos Defensores Públicos (Anadep). Os resultados da pesquisa sobre a implantação do programa institucional de assistência judiciária no Brasil mostram que a defensoria está presente apenas em $28 \%$ das comarcas brasileiras. Ou seja, só há defensores em 754 das 2.680 comarcas (Moura et al., 2013, p. 33).

Ao analisarem a relação entre vulnerabilidade social e Defensoria Pública no Brasil, os autores optaram pelo critério da renda. No estudo, foi considerado o recorte de até três salários mínimos como a população em potencial para utilização dos serviços públicos de assistência judicial, mesmo que não haja um limite legal estabelecido para dispor da defensoria. Segundo o Ministério da Justiça, a relação entre o público-alvo da defensoria (pessoas com remuneração de até três salários mínimos) e o número de defensores deve ser de 1 defensor público para 10.000 pessoas ou, no máximo, 15.000 . Se considerarmos o Brasil inteiro, a relação é de 1 para 18.336 com os cargos já criados por lei. Entretanto, a relação é de 1 defensor para 56.620 pessoas na faixa de utilização do serviço, caso sejam levados em consideração os defensores contratados e ativos.

Por fim, cabe citar o levantamento de dados sobre a presença dos órgãos do Judiciário nos estados e municípios brasileiros realizado pelo Ministério da Justiça em 2014 - o Atlas de Acesso à Justiça (Brasil, 2014). O objetivo do projeto foi mapear todo o sistema de proteção e de efetivação de direitos individuais e coletivos no país, a fim de facilitar o conhecimento pelos cidadãos de seus direitos fundamentais, além de criar um extenso banco de dados sobre as dimensões judiciais e extrajudiciais da justiça brasileira. 
No relatório Atlas de acesso à justiça: indicadores nacionais de acesso à justiça (Brasil, 2014, p. 15), os autores expressam a dificuldade de mensuração do conceito de acesso à justiça, uma vez que o fenômeno apresenta características sociais, econômicas e institucionais. Para criar um indicador geral de acesso à justiça no país, os autores separaram o fenômeno em duas dimensões: institucional, que corresponde às unidades jurisdicionais e extrajudiciais que oferecem os serviços judiciais; e a socioeconômica, que é a demanda pelos serviços judiciais.

O Indicador de Acesso à Justiça (Inaj) corresponde à razão da dimensão institucional pela dimensão socioeconômica. No relatório, ao avaliar a variação do Inaj em conjunto com o IDH dos estados da federação, percebeu-se que há uma correlação entre os dois indicadores, de modo que as localidades mais vulneráveis socialmente apresentam uma demanda reprimida pelos serviços judiciais.

Diante do exposto, percebe-se a centralidade da relação entre a expansão territorial do Judiciário e os indicadores socioeconômicos para a literatura contemporânea do acesso à justiça no Brasil. Apesar de a presença das varas judicias não ser o único indicador utilizado nas análises, a criação assimétrica das unidades reflete os obstáculos econômicos, sociais e territoriais presentes na prestação do serviço judicial. Portanto, o estudo da expansão da Justiça do Trabalho contribui não só para incluir ramos mais especializados e sensíveis nos debates, mas também para verificar se os padrões encontrados na literatura continuam a ser reproduzidos na dinâmica atual do Poder Judiciário.

\section{A Justiça do Trabalho no Brasil: crescimento e institucionalização}

O grande marco para a regulamentação das relações de trabalho no Brasil foi a Revolução de 1930, que alavancou o processo de industrialização no país. Em 1932, surge o precursor do sistema de solução judicial de conflitos trabalhistas, todavia apenas os integrantes do sindicalismo oficial poderiam fazer demandas ao órgão (Delgado, 2009, p. 103). Inicialmente, era uma espécie de justiça administrativa, ou seja, parte do Poder Executivo, visto que cabia recurso para o Ministério do Trabalho. Além do mais, o novo órgão não tinha competência para executar suas próprias decisões, que precisavam ser remetidas para a justiça comum ao final do processo (Silva, 2011, p. 78).

O consenso político necessário para a criação da Justiça do Trabalho foi costurado a partir da liderança do grupo corporativista, que argumentava no sentido de que "os conflitos entre empregadores e empregados não eram meramente de interesse privado, como no velho e morto liberalismo, mas que o Estado devia intervir neles sob uma Constituição onde a ordem econômica seja submetida à disciplina do Estado" (Oliveira Viana, apud Morel e Pessanha, 2006, p. 35). Entretanto, com a forte reação liberal, no Congresso Nacional, que teve a relatoria na Comissão de Constituição e Justiça, o impasse só foi decidido no Estado Novo de Vargas. 
Considera-se que o nascimento da Justiça do Trabalho esteja na Constituição de 1937 e no Decreto-Lei n 1.237/1939 (Morel e Pessanha, 2007, p. 80). O decreto prevê a criação de três instâncias para o julgamento das lides trabalhistas. Na base estavam as Juntas de Conciliação e Julgamento, que tinham como presidente um juiz de direito ou bacharel nomeado pelo presidente da República para o mandato de dois anos e também havia mais dois juízes classistas, que eram indicados pelos sindicatos dos patrões e empregados. Por conseguinte, cada junta possuía três membros (Morel e Pessanha, 2007, p. 90).

Na segunda instância, foram criados os Conselhos Regionais do Trabalho para a apreciação dos recursos. Os conselhos estavam distribuídos em oito regiões: $1^{a}$ região Rio de Janeiro; $2^{a}$ - São Paulo; $3^{a}$ - Belo Horizonte; 4a - Porto Alegre; $5^{a}$ - Salvador; 6a Recife; $7^{a}$ - Fortaleza; $8^{a}$ - Belém. No momento da promulgação do Decreto-Lei $n^{\circ}$ 1.237/1939, foram estabelecidas 36 Juntas de Conciliação e Julgamento, localizadas nas regiões mencionadas acima (Morel e Pessanha, 2007, p. 90). Também havia a representação classista e paritária entre patrões e empregados nos Conselhos Regionais.

Por fim, foi criado o Conselho Nacional do Trabalho, que funcionava como o órgão de cúpula da Justiça do Trabalho e era integrado por 19 membros nomeados pelo presidente da República: quatro membros representantes dos empregados, quatro representantes dos empregadores, quatro funcionários do Ministério do Trabalho e sete pessoas de reconhecido saber, sendo quatro formadas em direito (Morel e Pessanha, 2007, p. 90). A Justiça do Trabalho foi inaugurada no dia $1^{\circ}$ de maio de 1941.

Considera-se que a Justiça do Trabalho continuou como justiça administrativa durante seus primeiros anos, uma vez que a Constituição de 1937 incluiu suas disposições dentro do capítulo do Poder Executivo e não no do Judiciário. Apenas a Carta de 1946 completou o processo de criação quando incorporou a Justiça do Trabalho ao sistema judicial, tornando-a completamente independente do Poder Executivo. Foi nessa mudança que os Conselhos Regionais passaram a se chamar Tribunais Regionais do Trabalho e o Conselho Nacional se transformou no Tribunal Superior do Trabalho (Delgado e Delgado, 2011, p. 106).

Durante o período democrático entre 1946 e 1964, a Justiça do Trabalho começou a se integrar nas dinâmicas sociais e ganhar reconhecimento da comunidade como uma esfera de disputa efetiva não só para os conflitos individuais, mas também em relação aos processos de dissídios coletivos. Segundo Larissa Rosa Corrêa, "a Justiça do Trabalho se transformou em terreno fértil para a construção de uma identidade da classe trabalhadora fomentada pela luta por direitos" (Corrêa, 2011, p. 216).

Mesmo durante a ditadura militar, que retirou algumas garantias trabalhistas como a estabilidade, a Justiça do Trabalho manteve suas características principais e se mostrou capaz de atravessar diversas mudanças político-institucionais pelas quais o país passou. A estrutura do órgão permaneceu a mesma na Constituição de 1967 e também não foi alterada pela Emenda Constitucional de 1969. Conforme destacam Morel e 
Pessanha (2007, p. 91), no decurso do período autoritário, a Justiça do Trabalho se consolidou como um dos poucos espaços de defesa de direitos sociais.

Com a redemocratização, houve uma expansão para os locais mais distantes do país e uma ampliação significativa no acesso. Em 1988, existiam cerca de 490 varas e em 2009 o número chegou a 1.370, ou seja, um crescimento de $180 \%$ em duas décadas (Delgado e Delgado, 2011, p. 112). Atualmente, o número já ultrapassa as 1.500 varas. Conforme os dados apresentados por Cardoso (2002, p. 455), a criação de novas Juntas de Conciliação e Julgamento acompanhou o aumento da demanda pelos serviços judiciais, considerando o país de forma geral. Especialmente após 1987, a explosão no número de processos acolhidos é acompanhada do aumento significativo da estrutura judiciária trabalhista, indicada pelo número de varas.

Em 1999, por meio da Emenda Constitucional no 24, foi decretado o fim da representação classista em todos os órgãos da Justiça do Trabalho. Nesse momento, as Juntas de Conciliação e Julgamento passaram a se chamar varas do trabalho e passaram a ser compostas apenas por juízes togados - titulares e substitutos - decidindo monocraticamente.

A reforma do Judiciário, ocorrida em 2004, que, segundo Arantes (2014, p. 53), chegou a cogitar abertamente a extinção da Justiça do Trabalho, terminou por fortalecêla ainda mais. A Emenda Constitucional 45/2004 substituiu o termo relações de emprego (com carteira assinada) para relações de trabalho ao estabelecer a competência da Justiça do Trabalho, de forma que houve uma grande ampliação nas possibilidades de postulação. Antes de 2004, a competência era restrita aos vínculos empregatícios formais, com a reforma essa condição foi retirada. Além dessa mudança, a reforma constitucional do Judiciário trouxe para o âmbito da justiça trabalhista a competência para julgar casos envolvendo acidentes de trabalho.

\section{Procedimento para criação de varas do trabalho}

O procedimento padrão para o surgimento de uma nova vara do trabalho acontece por meio de lei ordinária, conforme determina o artigo 122 da Constituição Federal. A competência privativa para propor a criação de uma nova vara do trabalho foi conferida aos Tribunais Regionais do Trabalho, segundo o artigo 96, inciso I, alínea "d", da Constituição. Para que o anteprojeto de lei propondo a criação de varas surja, é preciso que o pleno do tribunal, composto pelos desembargadores, aprecie e aprove a proposta.

Em relação aos critérios legais para distribuição das unidades e dos magistrados, a Constituição Federal dispõe que o número de juízes deverá ser proporcional à efetiva demanda judicial e à respectiva população da localidade (art. 93, inc. XIII). Portanto, o princípio norteador da organização física da estrutura judiciária é a necessidade local. Em 2010, o Conselho Superior da Justiça do Trabalho, órgão que atua junto ao Tribunal 
Superior do Trabalho, através da Resolução 63/2010, determinou o limite mínimo de 24 mil trabalhadores no município para que seja criada uma nova unidade. Nas décadas anteriores, contudo, não havia nenhum limite.

Após a aprovação da proposta de criação no pleno do Tribunal Regional do Trabalho, o anteprojeto de lei segue para o Conselho Superior da Justiça do Trabalho, que é o responsável pela supervisão administrativa, orçamentária, financeira e patrimonial da Justiça do Trabalho, atuando como órgão central do sistema, conforme dispõe seu próprio regimento interno. A decisão do Conselho Superior da Justiça do Trabalho a respeito do anteprojeto de lei que propõe a criação de varas trabalhistas é vinculante. Caso a proposta seja rejeitada nessa fase, ela será arquivada e não segue adiante. Se for aprovada, segue para o Conselho Nacional de Justiça, que emitirá um parecer de mérito.

O parecer de mérito do Conselho Nacional de Justiça não é vinculante, porém, caso seja contrário, torna bastante improvável a aprovação do projeto. Após a análise do CNJ, o anteprojeto finalmente segue para o Congresso Nacional. Os projetos de lei de iniciativa do Poder Judiciário se direcionam para a Câmara dos Deputados e, consequentemente, o Senado Federal atua como casa revisora. A partir desse momento, o projeto de lei segue o processo legislativo assim como todos os outros e, inclusive, está sujeito à sanção do presidente da República.

\section{Modelo formal e metodologia}

Com o objetivo de desvendar quais são os fatores determinantes para a criação das varas do trabalho no período entre 2003 e 2010, é realizado o seguinte modelo de regressão logística:

$$
\begin{gathered}
y_{i}=\beta_{0}+\beta_{1} P E A+ \\
\beta_{2} D V A R A+\beta_{3} E J U D+\beta_{4} R E N D+\beta_{5} E D U C-\beta_{6} D C A P+\beta_{7} E A G R O+ \\
\beta_{8} E I N D+\beta_{9} E C O N S+\beta_{10} E C O M E+\beta_{11} E S E R V+\epsilon_{i}
\end{gathered}
$$

Na equação, $y_{i}$ corresponde à variável dependente, que é categórica binária e representa o recebimento ou não de uma vara do trabalho no município; $\beta_{0}$ é a constante do modelo; $\beta_{1} P E A$ representa a variável explicativa contínua correspondente à população economicamente ativa do município; $\beta_{2} D V A R A$ mede a distância do município para a vara do trabalho mais próxima; $\beta_{3} E J U D$ representa a estrutura judicial presente na localidade, medida pelo número de varas do trabalho em funcionamento; $\beta_{4} R E N D$ indica a renda per capita do município. O termo $\beta_{5} E D U C$ representa a taxa de frequência bruta ao ensino superior no município; $\beta_{6} D C A P$ corresponde à variável contínua que indica a distância em quilômetros do município em relação à capital do estado em que se localiza; $\beta_{7} E A G R O$, $\beta_{8} E I N D, \beta_{9} E C O N S, \beta_{10} E C O M E, \beta_{11} E S E R V$ representam, respectivamente, a proporção de 
indivíduos ocupados no setor agropecuário, na indústria de transformação, no setor de construção, no setor de comércio e no setor de serviços; $\epsilon_{i}$ é o termo de erro.

A variável dependente, que corresponde ao recebimento ou não de uma vara trabalhista no município durante o período analisado, é uma forma de mensuração do acesso à justiça. Naturalmente, a prestação do serviço jurisdicional não se resume à existência física do órgão judicial. Há diversas outras questões fundamentais, tal como o tempo de duração do processo. Porém, a presença do Judiciário é o primeiro passo para a resolução dos conflitos, conforme demonstra a utilização dessa variável na literatura empírica na ciência política interessada no acesso à justiça. Durante o período 20032010, a criação de varas do trabalho por meio de legislação ocorreu somente com a Lei $n^{\circ} 10.770 / 2003$. Foram inseridas na análise apenas as varas que foram efetivamente instaladas.

Em relação às variáveis independentes, a primeira delas é a população economicamente ativa (PEA) do município, que é uma proxy da demanda judicial da localidade. Considerando que não temos acesso aos dados da movimentação processual de todas as comarcas brasileiras em termos de litígios trabalhistas, a PEA é o indicador que melhor representa essa demanda, uma vez que se espera que, quanto maior a população economicamente ativa, maior será a utilização dos serviços judiciais, inclusive na Justiça do Trabalho. Além do mais, a população também aparece na Constituição Federal como critério base para a criação das varas. Portanto, tendo em vista a centralidade do critério populacional na legislação, espera-se que essa variável tenha um forte poder explicativo nos dois modelos.

A distância para a vara do trabalho mais próxima ao munícipio e a estrutura judicial referente às varas do trabalho em funcionamento na localidade também foram adicionadas ao modelo. Espera-se que, quanto maior a distância geográfica do município para uma vara, maior será a probabilidade de que o local seja contemplado na expansão da Justiça do Trabalho. Por outro lado, se o município já possui uma ou mais varas do trabalho, é possível esperar maior chance de recebimento de novas unidades, uma vez que o custo para implantação é menor. Ambas as variáveis foram mensuradas no período imediatamente anterior à Lei n 10.770/2003.

Em seguida, a variável explicativa apresentada no modelo é a renda per capita do município e o indicador de escolaridade, que mede a proporção de pessoas cursando o ensino superior na localidade. Espera-se que, quanto maior a renda e a escolaridade, maior seja a probabilidade de um município receber uma vara trabalhista. Conforme detalhado anteriormente, a literatura especializada encontrou uma forte relação entre a presença das varas da justiça comum e o IDH municipal, por isso o IDH foi desagregado para verificar qual dos dois fatores tem maior impacto na criação das varas trabalhistas.

A distância do município para a capital do estado da federação respectivo também será utilizada como variável independente. É comum haver cidades-satélite na periferia das grandes capitais ou na região metropolitana, que, apesar da população 
reduzida, apresentam uma maior chance de receber varas judiciais em virtude de serem cidades-dormitório e apresentarem uma elevada demanda por serviços do Judiciário. Consequentemente, espera-se que, quanto menor a distância do município para a capital do estado, maior será a probabilidade de que ele receba uma vara trabalhista.

A fim de testar outras variáveis econômicas para além da renda per capita, inserimos no modelo a proporção de pessoas com mais de 18 anos ocupadas em setores diversos da economia. Com isso, é possível delinear melhor o perfil dos municípios que recebem as varas. Ressalva-se que as proporções de indivíduos empregados no setor extrativo mineral e no setor de serviços industriais de utilidade pública (Siup) foram excluídas da análise em virtude do grande número de casos sem os valores respectivos.

A unidade de análise deste artigo não são as varas do trabalho, mas sim todos os municípios brasileiros existentes em 2000, que podem ter recebido uma vara ou não. Considerando que a variável dependente no modelo é categórica e binária (município recebeu ou não recebeu vara de trabalho), a técnica de análise que usamos é a regressão logística. Embora alguns municípios tenham recebido mais de uma vara do trabalho durante a década, optamos por codificar a variável dependente como o fato de ter recebido ou não alguma unidade da Justiça do Trabalho no período, visto que foram poucas as cidades que receberam mais de uma, o que poderia causar uma distorção na utilização de outros tipos de regressões.

Em relação aos dados coletados, utilizamos o Atlas do Desenvolvimento Humano ${ }^{3}$ para mensurar a renda per capita, a população economicamente ativa, a taxa de frequência bruta no ensino superior e a proporção de ocupados em cada setor da economia. As variáveis referentes às varas do trabalho foram codificadas por meio de informações obtidas no Tribunal Superior do Trabalho; o departamento de estatística disponibiliza a data de criação e instalação de todas as varas trabalhistas existentes no país, inclusive as que anteriormente eram as Juntas de Conciliação e Julgamento.

Para calcular a distância para a vara do trabalho mais próxima foi utilizado o arquivo de dados geoespaciais do Centro de Estudos da Metrópole (2013), porque se mede a localização municipal através de sua sede e posição central, ao contrário de um centroide projetado que consideraria os limites municipais como um todo. Portanto, está se medindo a distância da localização central de um município para outro, de forma que, se um município não possui vara do trabalho, é possível mensurar a distância para o mais próximo deste que a possua. Os cinco municípios presentes na base de dados criada após o período analisado foram excluídos. No cálculo da distância para a capital do estado da federação, foi utilizada uma versão do banco de dados com os estados.

\footnotetext{
3 Disponível em: <http://atlasbrasil.org.br>. Acesso em: 17 jul. 2018.
} 


\section{A expansão da Justiça do Trabalho em 2003-2010}

Iniciamos a análise pela visualização do mapa dos municípios que receberam uma vara do trabalho durante a década em contraste com o Índice de Desenvolvimento Humano Municipal.

\section{Mapa 1}

\section{IDHM dos municípios brasileiros (2000)}

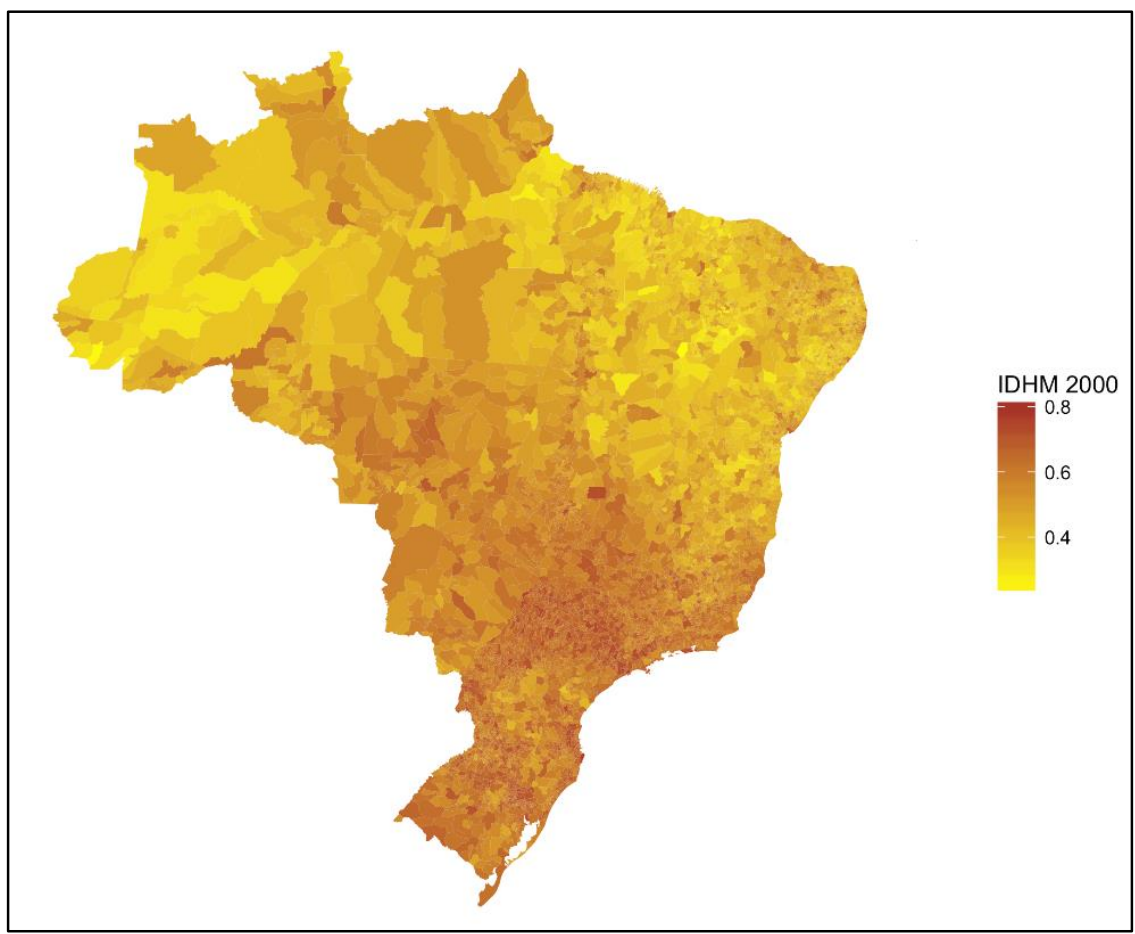

Fonte: Elaboração própria a partir dos dados do Atlas de Desenvolvimento Humano. 

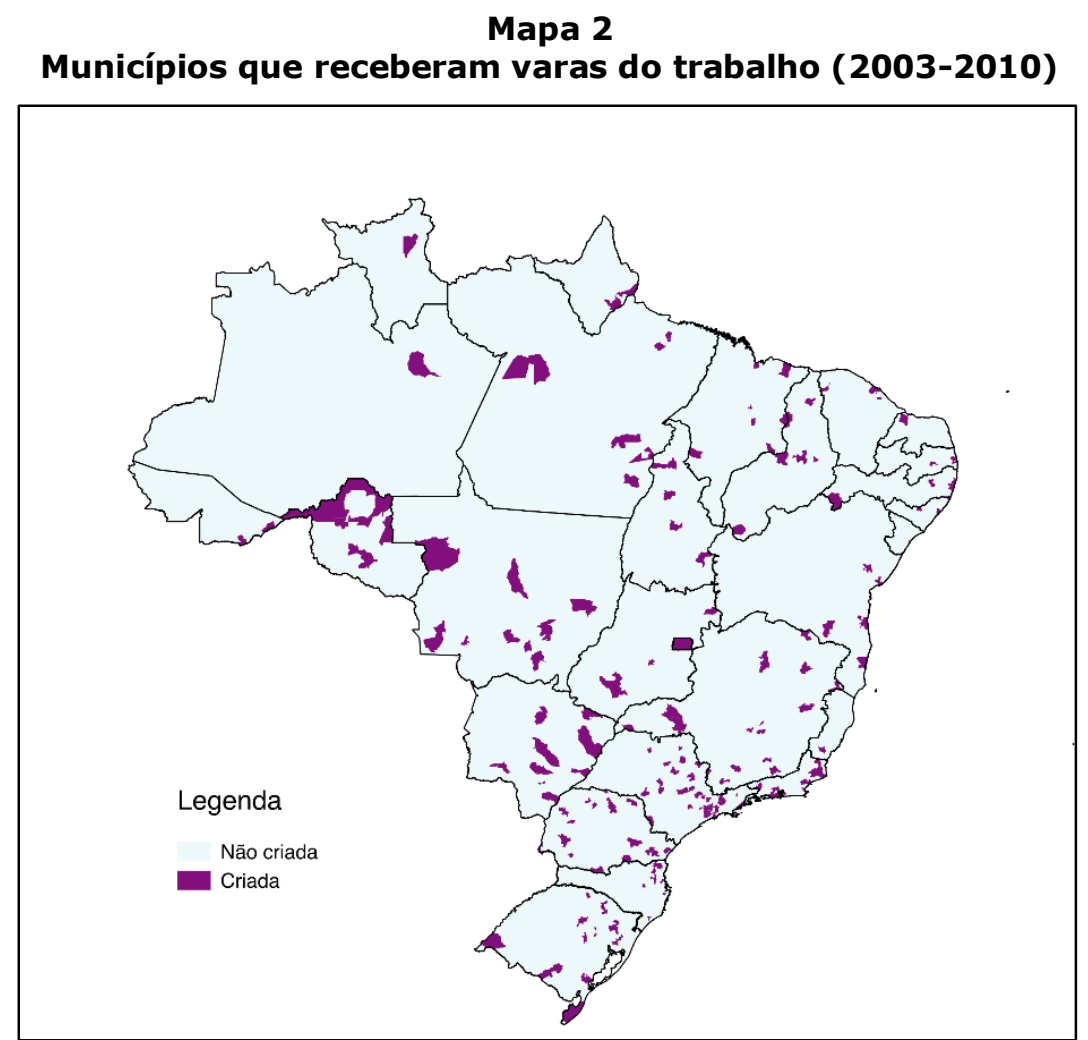

Fonte: Elaboração própria a partir dos dados do Tribunal Superior do Trabalho.

A partir da visualização do mapa, não é possível perceber um padrão específico de relação da criação das varas com o IDHM. Embora no Norte do país, por exemplo, em Roraima e no Amapá, haja a coincidência do recebimento das varas com um alto IDHM, os casos se referem aos municípios de Boa Vista e Macapá, que são as capitais dos estados e, por isso, concentram a estrutura dos órgãos judiciais. Em Rondônia, além da capital Porto Velho, outros municípios mais afastados e com menor IDHM, como São Miguel do Guaporé, também receberam unidades. No Nordeste, há uma quantidade considerável de varas criadas em cidades distantes do litoral, que tendem a ter um desenvolvimento socioeconômico menor em média. No sertão nordestino, destaca-se o recebimento por parte de centros regionais como Petrolina e Campina Grande.

A região mais beneficiada com a expansão em 2003-2010 foi o Sudeste, com 69 unidades. Considerando que a população da região Sudeste é a maior do país, o resultado já era esperado. Porém, o Nordeste recebeu 41 varas e tinha quase o dobro da população da região Sul, que foi contemplada com 46 unidades. A região Centro-Oeste recebeu 23 e a Norte, 22 varas. Os cinco estados da federação que aparecem nos primeiros lugares são: São Paulo, Paraná, Minas Gerais, Rio Grande do Sul e Rio de Janeiro. Portanto, ao observar o recorte entre as regiões do país, percebe-se que o 
Nordeste não recebeu um número proporcional de unidades em termos populacionais. Entretanto, é preciso fazer a análise no nível municipal para chegar a resultados conclusivos sobre a criação das varas. Na Tabela 1 segue a análise do modelo de regressão para o período:

Tabela 1

Determinantes para o recebimento das varas do trabalho (2003-2010)

\begin{tabular}{|c|c|c|c|c|c|c|c|}
\hline \multirow{2}{*}{ Determinantes } & \multicolumn{7}{|c|}{ Modelo } \\
\hline & 1 & 2 & 3 & 4 & 5 & 6 & 7 \\
\hline $\begin{array}{l}\text { População } \\
\text { economicamente } \\
\text { ativa }\end{array}$ & $\begin{array}{c}1,444 \\
(0,00)^{* *}\end{array}$ & & & & & & $\begin{array}{c}1,399 \\
(0,00)^{* *}\end{array}$ \\
\hline Educação superior & & $\begin{array}{c}1,127 \\
(0,00)^{* *}\end{array}$ & & & & & $\begin{array}{c}1,054 \\
(0,00)^{* *}\end{array}$ \\
\hline Estrutural judicial & & & $\begin{array}{c}3,430 \\
(0,00) * *\end{array}$ & & & & $\begin{array}{c}0,473 \\
(0,00) * *\end{array}$ \\
\hline $\begin{array}{l}\text { Distância para vara } \\
\text { mais próxima }\end{array}$ & & & & $\begin{array}{c}0,853 \\
(0,00)^{* *} \\
\end{array}$ & & & $\begin{array}{c}1,119 \\
(0,00) * *\end{array}$ \\
\hline $\begin{array}{l}\text { Distância para capital } \\
\text { do estado }\end{array}$ & & & & & $\begin{array}{c}0,710 \\
(0,00)^{* *}\end{array}$ & & $\begin{array}{l}1,024 \\
(0,71)\end{array}$ \\
\hline Renda & & & & & & $\begin{array}{c}1,157 \\
(0,00) * *\end{array}$ & $\begin{array}{l}1,016 \\
(0,81) \\
\end{array}$ \\
\hline $\begin{array}{l}\text { Ocupados no setor } \\
\text { agropecuário }\end{array}$ & & & & & & $\begin{array}{l}0,987 \\
(0,78)\end{array}$ & $\begin{array}{l}0,964 \\
(0,42)\end{array}$ \\
\hline $\begin{array}{l}\text { Ocupados na } \\
\text { indústria de } \\
\text { transformação }\end{array}$ & & & & & & $\begin{array}{l}1,046 \\
(0,33)\end{array}$ & $\begin{array}{l}1,007 \\
(0,88)\end{array}$ \\
\hline $\begin{array}{l}\text { Ocupados no setor } \\
\text { de construção }\end{array}$ & & & & & & $\begin{array}{l}0,938 \\
(0,27) \\
\end{array}$ & $\begin{array}{c}0,978 \\
(0,70) \\
\end{array}$ \\
\hline $\begin{array}{l}\text { Ocupados no setor } \\
\text { de comércio }\end{array}$ & & & & & & $\begin{array}{c}1,238 \\
(0,00)^{* *}\end{array}$ & $\begin{array}{c}1,166 \\
(0,00)^{* *}\end{array}$ \\
\hline $\begin{array}{l}\text { Ocupados no setor } \\
\text { de serviços }\end{array}$ & & & & & & $\begin{array}{l}1,081 \\
(0,11) \\
\end{array}$ & $\begin{array}{l}1,003 \\
(0,95) \\
\end{array}$ \\
\hline Constante & $\begin{array}{c}0,014 \\
(0,00)^{* *}\end{array}$ & $\begin{array}{c}0,012 \\
(0,00)^{* *}\end{array}$ & $\begin{array}{c}0,022 \\
(0,00)^{* *}\end{array}$ & $\begin{array}{c}0,067 \\
(0,00)^{* *}\end{array}$ & $\begin{array}{c}0,078 \\
(0,00)^{* *}\end{array}$ & $\begin{array}{c}0,000 \\
(0,04)^{* *}\end{array}$ & $\begin{array}{l}0,003 \\
(0,20)\end{array}$ \\
\hline $\begin{array}{l}\text { Pseudo } R^{2} \\
\text { (Nagelkerke test) }\end{array}$ & 0,363 & 0,122 & 0,230 & 0,030 & 0,030 & 0,387 & 0,484 \\
\hline
\end{tabular}

Fonte: Elaboração própria a partir de dados do Tribunal Superior do Trabalho e do Atlas do Desenvolvimento Humano.

Significância: $* * p<0,05 . * p<0,10 . N=5.565$.

Os coeficientes estão expostos em razão das chances, porque a interpretação por meio do logaritmo não é intuitiva. Foi necessário alterar as casas das variáveis correspondentes a população economicamente ativa (PEA), renda per capita, distância para a capital do estado e distância para a vara do trabalho mais próxima, uma vez que a diferença de uma unidade da variável gera um impacto muito pequeno. A população economicamente ativa, por exemplo, foi dividida por 10 mil, de modo que o coeficiente expressa a razão das chances entre um município e outro que tem 10 mil pessoas na PEA a mais. Sem considerar o efeito de outras variáveis (modelo 1), apenas essa diferença na PEA acarreta, em média, $44 \%$ a mais de chance para que o município receba uma vara. 
AONDE CHEGA O JUDICIÁRIO? UMA AVALIAÇÃO DA EXPANSÃO DA JUSTIÇA DO TRABALHO NO BRASIL (2003-2010)

A renda, por sua vez, foi dividida por 100, de forma que o coeficiente apresentado representa a razão das chances comparando um município e outro com uma renda per capita de $\mathrm{R} \$ 100$ a mais. A distância para a capital do estado da federação e a distância para a vara do trabalho mais próxima foram divididas por 100 e 10, respectivamente, a fim de também facilitar a interpretação do coeficiente. A taxa bruta de frequência no ensino superior e os ocupados em cada setor da economia são medidos em termos percentuais, portanto, o coeficiente mensura a razão das chances entre um município e outro com um ponto percentual a mais. Por fim, a variável referente à estrutura judicial mede o impacto da quantidade de varas que o município já possui no recebimento de novas unidades.

Quando a renda per capita é colocada em conjunto com as outras variáveis econômicas no modelo 6 , o efeito é significativo estatisticamente. 0 coeficiente demonstra que municípios com $\mathrm{R} \$ 500$ de renda per capita receberiam 11 unidades judiciárias para que municípios com $R \$ 400$ recebessem 10 . No entanto, no modelo 7 , em que a renda per capita é testada com todos os outros fatores, não há significância estatística. Ou seja, o impacto da renda per capita no recebimento das varas do trabalho deixa de ser relevante ao inserir variáveis não econômicas na análise.

Por outro lado, o indicador referente ao número proporcional de habitantes frequentando a universidade manteve a significância estatística no modelo com todas as variáveis. O coeficiente indica que um município com $20 \%$ a mais que outro na proporção de indivíduos no ensino superior receberia o dobro de varas do trabalho, mantendo todos os outros fatores constantes. Portanto, pode-se afirmar que os municípios mais desenvolvidos em termos educacionais foram mais contemplados na expansão da Justiça do Trabalho durante o período.

A população economicamente ativa manteve um efeito relevante estatisticamente não só quando analisada separadamente, mas também em conjunto com todos os controles. O modelo 7 indica que, a cada 10 mil pessoas a mais na PEA, aumenta-se em $40 \%$ a chance de o município receber uma vara do trabalho. Consequentemente, entre 2003 e 2010, de acordo com os dados, pode-se concluir que um município com 60 mil pessoas na PEA receberia três varas para que outro com 10 mil recebesse uma. 0 resultado demonstra que o critério populacional estabelecido pela Constituição Federal foi respeitado durante o período de 2003 a 2010.

A variável que leva em consideração a distância para a vara do trabalho mais próxima também foi importante para explicar a variação no recebimento das unidades judiciárias. Sem considerar a população economicamente ativa e os demais controles, o efeito foi negativo, ou seja, quanto menor a distância para uma vara do trabalho, maior a chance de recebimento. Porém, o sinal da relação se inverteu quando todas as variáveis foram inseridas na análise, de modo que um município distante 100 quilômetros de uma unidade da Justiça do Trabalho teria, aproximadamente, o dobro de chance de receber uma vara comparado com outro que estivesse a apenas 10 quilômetros de distância. 
A medida referente à estrutura judicial também mudou o sinal do efeito no modelo 7. Ao ser analisada isoladamente, quanto maior o número de varas do trabalho no município, maior a chance de receber outras. Contudo, quando as outras variáveis são mantidas constantes, o coeficiente demonstra que um município com uma vara do trabalho a mais do que outro teria cerca de metade da chance de receber uma unidade. Por conseguinte, apesar de o custo de instalação de uma nova vara ser menor em locais onde já existam unidades, no período 2003-2010, os municípios com menos varas foram mais contemplados na expansão da Justiça do Trabalho.

A distância para a capital do estado da federação deixou de apresentar significância estatística quando se leva em consideração todas as variáveis. Embora ao ser analisada separadamente essa variável indique que os municípios mais próximos das capitais dos estados receberam mais varas do trabalho, o resultado do modelo 7 demonstra que essa proximidade é indiferente ao controlar pela população e outras características dos municípios.

Em relação às variáveis do percentual de ocupados nos setores da economia, apenas o setor de comércio teve um resultado significativo. Considerando que o coeficiente indica que, a cada ponto percentual adicional de ocupados no setor de comércio, há $16,6 \%$ a mais de chance de receber uma vara, o efeito é relevante. Um município com $6 \%$ a mais de ocupados no setor de comércio do que outro, mantendo todos os outros fatores constantes, receberia uma vara do trabalho a mais.

Em suma, entre 2003 e 2010, em termos de critérios socioeconômicos, os municípios com maior número de pessoas na população economicamente ativa, com mais indivíduos proporcionalmente cursando o ensino superior e com mais trabalhadores ocupados no setor de comércio receberam mais varas da Justiça do Trabalho de acordo com os dados. O fator geográfico também foi importante e os municípios mais distantes das unidades judiciárias já existentes foram mais contemplados na expansão. As localidades que ainda não possuíam uma vara do trabalho ou com menos unidades tiveram mais oportunidade de receber uma.

Para medir o ajuste do modelo, optamos por apresentar o pseudo $\mathrm{R}^{2}$ por meio da medida criada por Nagelkerke. Existem várias formas de apresentar o quanto é explicado pelos dados na regressão logística, porém não há um consenso sobre qual seria o cálculo mais adequado. Conforme Menard (2002, p. 20), na regressão linear, o R² é a "variância explicada", que serve para determinar se a relação é forte o suficiente para ser levada em consideração. Na regressão logística, talvez a medida de $\mathrm{R}^{2}$ mais conhecida seja o teste de Cox e Snell, entretanto nesse cálculo o limite máximo não é 1.0 como no $\mathrm{R}^{2}$ da regressão linear, tornando a interpretação pouco intuitiva, já que o máximo normalmente é 0.75 e pode chegar a $0.48 \mathrm{em}$ alguns casos. A medida criada por Nagelkerke corrige esse problema ao ajustar a medida para que ela se apresente entre 0 e 1.0 , por isso optamos por reportar dessa forma neste artigo. Todavia, é importante acrescentar que, 
de todo modo, a medida de ajuste do modelo em termos de pseudo $\mathrm{R}^{2}$ não é unanimidade e precisa ser observada com ressalvas.

No modelo 7, com todas as variáveis independentes, o teste de Nagelkerke apresentou um resultado de 0,484. Interpretando de acordo com a lógica do $\mathrm{R}^{2}$, significaria afirmar que as variáveis explicativas em conjunto explicam $48 \%$ da variação do recebimento das varas do trabalho, o que é uma quantidade relevante para uma pesquisa no campo das ciências sociais. É preciso destacar que somente a população economicamente ativa (modelo 1 ) é capaz de explicar $36 \%$ da variação da variável dependente, o que demonstra a centralidade da PEA para entender a expansão da Justiça do Trabalho durante o período.

Relação entre movimentação processual e criação de varas do trabalho na Lei $\mathbf{n}^{\circ}$ $10.770 / 2003$

Considerando que os dados sobre a movimentação do volume processual da Justiça do Trabalho entre 2000 e 2010 estão disponíveis somente de forma agregada por TRT, a análise será feita por tribunal. Foi realizada uma correlação entre as varas do trabalho criadas na Lei $n^{\circ} 10.770 / 2003$ e o número de processos recebidos e julgados e o resíduo na primeira instância em cada Tribunal Regional do Trabalho para verificar se o padrão de distribuição das varas por região apresenta relação estatística com o volume processual.

A correlação linear foi feita por meio do coeficiente desenvolvido por Pearson, que mede o grau e a direção da relação linear entre duas variáveis. Na Tabela 2, segue a matriz de correlação entre criação das varas do trabalho por TRT na Lei $n^{\circ} 10.770 / 2003$ e número de processos recebidos e julgados e resíduo por tribunal.

Tabela 2

Correlação entre a criação de varas do trabalho e a movimentação processual por TRT (2003)

\begin{tabular}{|l|c|c|c|}
\hline & Recebidos & Julgados & Resíduo \\
\hline Recebidos & - & - & - \\
\hline Julgados & $0,999 * *$ & - & - \\
\hline Resíduo & $0,914 * *$ & $0,902^{* *}$ & - \\
\hline Varas & $0,813^{* *}$ & $0,812^{* *}$ & $0,726 * *$ \\
\hline
\end{tabular}

Fonte: Tribunal Superior do Trabalho.

Significância: $* * p<0,05 . N=24$.

Os resultados demonstram que a criação das varas apresenta uma correlação positiva com os processos recebidos na primeira instância nos Tribunais Regionais do Trabalho, ou seja, quanto maior a quantidade de processos recebidos, maior o número de varas alocadas no tribunal. O coeficiente é significativo a 0,05 e também apresenta um valor acima de 0,80 , indicando uma forte relação entre as duas variáveis. 
A relação entre o número de processos julgados na primeira instância e a criação de varas do trabalho por tribunal também apresentou significância estatística e um alto coeficiente. Há um indicativo, portanto, de que as varas criadas também estão relacionadas com a produtividade na primeira instância. O número correspondente ao resíduo processual também foi relevante em termos explicativos, contudo, apresentou um coeficiente menor que o das outras duas variáveis. Os Gráficos 1, 2 e 3 apresentam os detalhes de cada correlação:

\section{Gráfico 1}

Correlação entre criação das varas e processos recebidos por Tribunal Regional do Trabalho em 2003

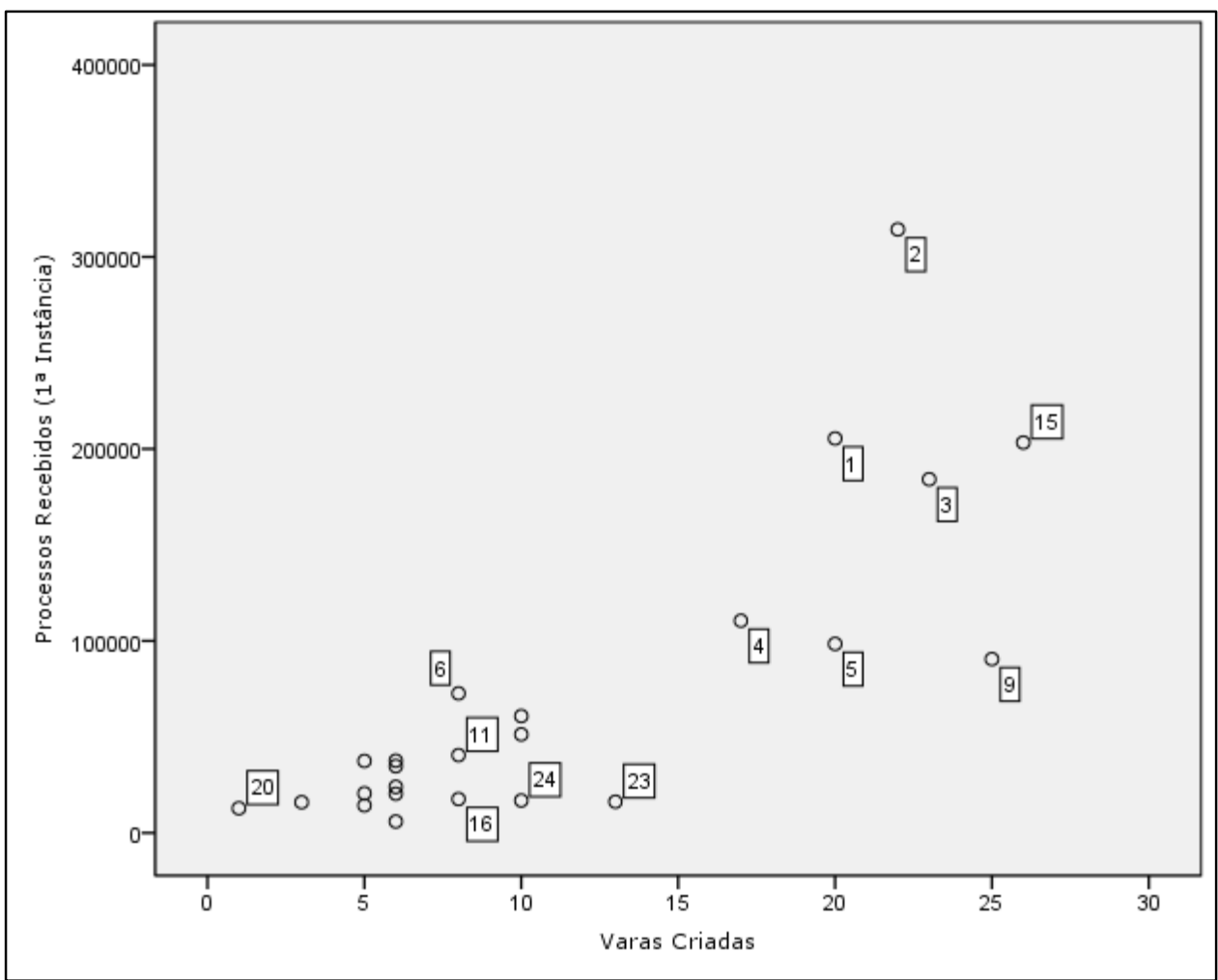

Fonte: Tribunal Superior do Trabalho. 
Gráfico 2

Correlação entre criação das varas e processos julgados por Tribunal Regional do Trabalho em 2003

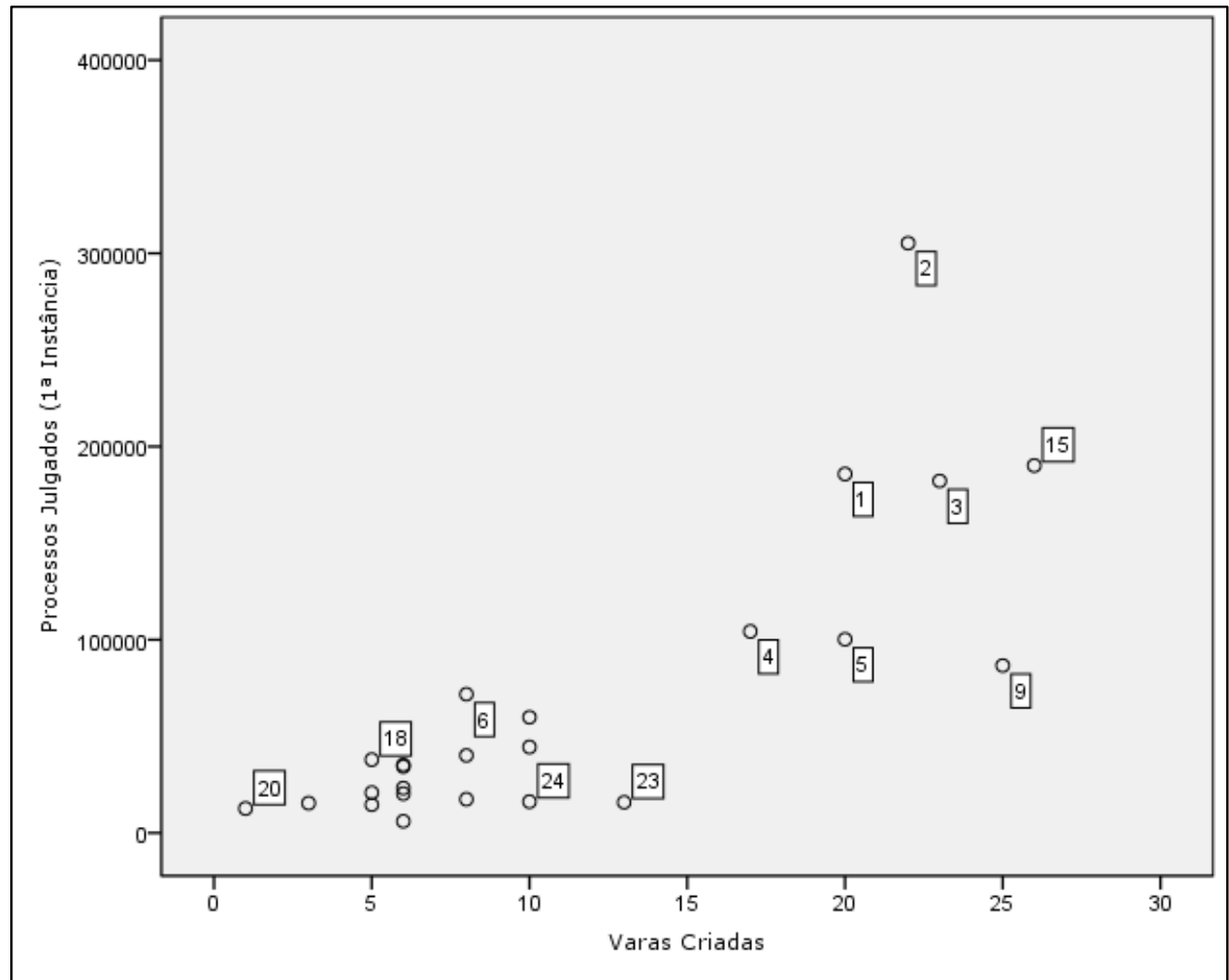

Fonte: Tribunal Superior do Trabalho. 


\section{Gráfico 3 \\ Correlação entre criação das varas e resíduo por Tribunal Regional do Trabalho em 2003}

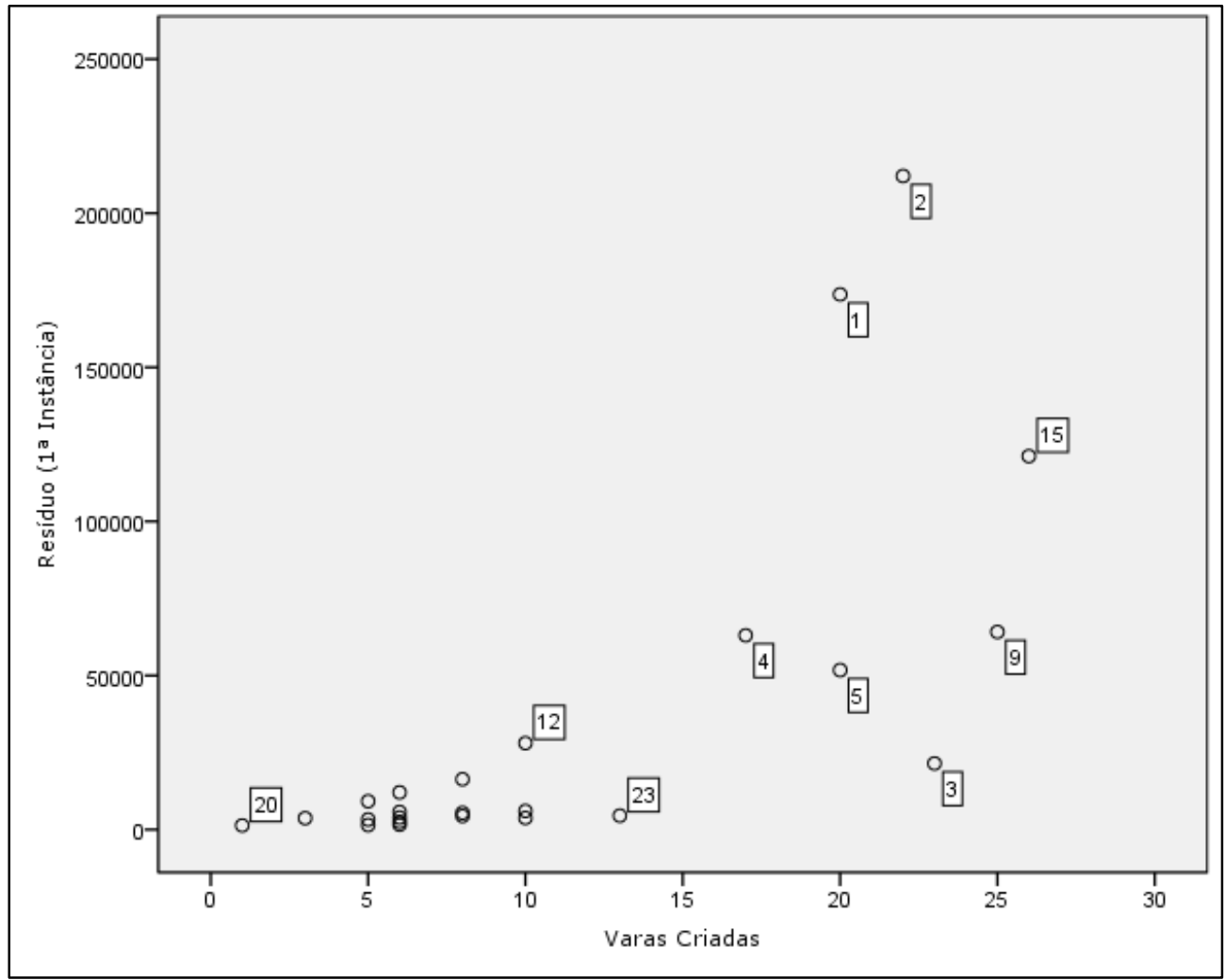

Fonte: Tribunal Superior do Trabalho.

Através da análise dos Gráficos 1, 2 e 3, percebe-se que embora haja uma relação linear entre as três variáveis e a criação das varas, alguns casos se destacam por estarem fora do padrão estabelecido na relação. Por exemplo, o TRT da 9a região responsável pelo estado do Paraná recebeu 25 varas na Lei $n^{\circ} 10.770 / 2003$, mesmo que o número de processos recebidos e julgados e resíduos tenha ficado abaixo dos 100 mil. Por sua vez, o TRT da $2^{a}$ região - capital de São Paulo e arredores - teve mais de 300 mil processos recebidos e julgados em 2003 e recebeu 22 varas.

É preciso ressaltar que no estado de São Paulo existem dois Tribunais Regionais do Trabalho. O TRT da $15^{a}$ região com sede na cidade de Campinas foi o tribunal contemplado com o maior número de varas na referida lei - 26 unidades. Além do Paraná, o TRT da $5^{a}$ região (Bahia) recebeu um número considerável de unidades jurisdicionais, apesar de não apresentar uma média substancialmente superior em termos processuais aos demais tribunais. Por exemplo, o TRT da $5^{a}$ região recebeu e 
julgou cerca de $30 \%$ de processos a mais que o TRT da $6^{\text {a }}$ região em Pernambuco, entretanto recebeu mais que o dobro de varas.

Os casos dos tribunais regionais da $1^{a}$ e $3^{a}$ região, Rio de Janeiro e Minas Gerais, respectivamente, demonstram uma relação interessante, visto que ambos os tribunais receberam e julgaram um número próximo de 200 mil processos e também receberam um número parecido de varas. Porém, o resíduo processual dos dois tribunais é bem distinto, enquanto em Minas Gerais o valor está próximo de 20 mil processos, no Rio de Janeiro ultrapassa 170 mil. Por conseguinte, nesse caso específico, o resíduo parece ter menor potencial explicativo em relação às outras variáveis.

Entre os tribunais que receberam menos de 50 mil processos em 2003, apenas os TRTs do Mato Grosso e Mato Grosso do Sul receberam 10 ou mais varas. Nos demais tribunais localizados no Rio Grande do Norte, Maranhão, Paraíba, Espírito Santo, Alagoas, Distrito Federal/Tocantins, Goiás, Ceará e Amazonas/Roraima, o número de varas recebidas variou entre três e oito. Nesses tribunais com menor volume processual, a relação linear entre os processos recebidos e a criação de varas foi mais acentuada, conforme é possível visualizar nos Gráficos 1 e 2.

\section{A aplicação dos critérios da Resolução 63/2010 do Conselho Superior da Justiça do Trabalho nas varas criadas entre 2010 e 2015}

$\mathrm{Na}$ Justiça do Trabalho, os principais critérios para criação de novas unidades judiciárias são estabelecidos especificamente pela Resolução 63/2010 do Conselho Superior da Justiça do Trabalho (CSJT). Apesar de o processo de criação das varas também passar pelo Conselho Nacional de Justiça e estar vinculado à Resolução $n^{\circ}$ 184/2013 do CNJ, as regras determinadas pelo CSJT são mais específicas.

É necessário destacar que antes de 2010 não havia critérios populacionais ou de movimentação processual para que fossem criadas novas varas. O artigo 9 da Resolução $63 / 2010$ determinou que, em localidade onde ainda não exista nenhuma vara, uma nova unidade só poderá ser criada se houver mais de 24 mil trabalhadores na base territorial prevista para a jurisdição ou o ajuizamento de pelo menos 350 reclamações trabalhistas por ano apuradas nos três anos anteriores.

Em termos populacionais, diversos municípios com menos de 24 mil trabalhadores receberam varas após 2010, porém a resolução estipula a base territorial da jurisdição como medida de referência. Considerando toda essa base territorial, apenas dois municípios ficam abaixo do limite populacional estabelecido pela resolução, ambos localizados no Mato Grosso: Sapezal e Alto Araguaia. No Quadro 1, seguem os dados sobre as ações ajuizadas, a fim de verificar se o critério mínimo de movimentação processual foi atendido nesses casos: 


\section{Quadro 1 \\ Municípios com menos de 24 mil trabalhadores na jurisdição que receberam a primeira vara do trabalho (2010-2015)}

\begin{tabular}{|c|c|c|c|c|c|}
\hline \multirow{2}{*}{ Município-sede } & \multirow{2}{*}{ TRT } & \multirow{2}{*}{$\begin{array}{l}\text { Número de } \\
\text { trabalhadores na } \\
\text { jurisdição ( } 2010 \text { ) }\end{array}$} & \multicolumn{3}{|c|}{ Ações ajuizadas } \\
\hline & & & 2009 & 2010 & 2011 \\
\hline Sapezal & 23 & 21.034 & 789 & 366 & 225 \\
\hline Alto Araguaia & 23 & 19.551 & 607 & 412 & 331 \\
\hline
\end{tabular}

Fonte: Tribunal Superior do Trabalho e Atlas do Desenvolvimento Humano.

As varas do trabalho de Sapezal e Alto Araguaia foram criadas pela Lei $\mathrm{n}^{\circ}$ 12.474/2011 a partir de projeto de lei apresentado em 9/7/2010 pelo Tribunal Superior do Trabalho. As ações ajuizadas no Quadro 1 se referem não apenas aos respectivos municípios, mas também a toda a jurisdição que foi atribuída às novas varas. No caso de Sapezal, a jurisdição abarca Campos de Júlio (MT) e Comodoro (MT), na vara de Alto Araguaia estão Alto Garças (MT), Alto Taquari (MT), Araguainha (MT) e Ponte Branca (MT).

A partir dos dados relatados acima, percebe-se que, embora ambos os municípios tivessem menos de 24 mil trabalhadores na jurisdição no momento da criação das unidades judiciárias, a média de ações ajuizadas foi superior ao limite mínimo estipulado pela Resolução 63/2010, que é de 350 ações. É possível observar, entretanto, que nos dois municípios o número de ações ajuizadas apresenta uma tendência de queda nos anos anteriores à criação das varas, o que é um padrão distinto do que se poderia esperar para localidades que estão recebendo novas unidades.

Outro município cujas características de movimentação processual chamam a atenção é Colniza (MT), que teve sua primeira vara do trabalho também criada pela Lei no 12.474/2011. Além da sede, a jurisdição da nova unidade abrangeu Cotriguaçu (MT), Aripuanã (MT) e Rondolândia (MT). O número de trabalhadores na base territorial da jurisdição ultrapassa os $30 \mathrm{mil}$ e, portanto, o critério estabelecido no artigo 9 da resolução foi atendido. Contudo, a soma das ações ajuizadas a partir desses quatro municípios apresenta uma média consideravelmente abaixo das outras localidades que receberam a primeira vara do trabalho no período. Em 2009, foram 202 ações, em 2010, 184, e, em 2011, apenas 97. Naturalmente, questões geográficas ou relacionadas à interiorização da Justiça do Trabalho podem ter sido fundamentais para a criação da vara de Colniza, no entanto apenas pesquisas futuras que analisem as deliberações feitas poderão esclarecer os motivos.

Na Resolução 63/2010, no caso dos municípios onde já existe uma unidade da Justiça do Trabalho em funcionamento, a regra é mais rígida. O Conselho Superior da Justiça do Trabalho acrescentou o $\S 1^{\circ}$ ao artigo 9 da resolução determinando que, nas localidades que já dispõem de uma vara do trabalho, é necessária uma média de 
processos recebidos igual ou superior a 1.500 para que seja proposta a criação de uma nova unidade. Apesar de o dispositivo não fazer referência ao limite mínimo de trabalhadores para o recebimento de uma nova vara, considera-se que o número de 24 mil trabalhadores é a referência em termos de população. Por isso, o Quadro 2 mostra a movimentação processual dos municípios com menos de 24 mil trabalhadores em 2010 que receberam a segunda vara do trabalho após a edição da Resolução 63 do CSJT:

\section{Quadro 2}

Municípios com menos de 24 mil trabalhadores que receberam a segunda vara do trabalho (2010-2015)

\begin{tabular}{|c|c|c|c|c|c|}
\hline \multirow{2}{*}{ Vara do trabalho } & \multirow{2}{*}{ TRT } & \multirow{2}{*}{$\begin{array}{c}\text { Número de } \\
\text { trabalhadores } \\
(2010)\end{array}$} & \multicolumn{3}{|c|}{ Processos recebidos } \\
\hline & & & 2009 & 2010 & 2011 \\
\hline Estrela & 4 & 18.562 & 1.838 & 979 & 1.022 \\
\hline Nazaré da Mata & 6 & 10.885 & 2.746 & 2.127 & 2.343 \\
\hline Palmares & 6 & 19.443 & 2.797 & 1.756 & 2.193 \\
\hline Ribeirão & 6 & 14.894 & 2.128 & 2.080 & 2.075 \\
\hline São Miguel dos Campos & 19 & 20.298 & 2.174 & 1.914 & 2.409 \\
\hline Macau & 21 & 11.930 & 2.208 & 1.556 & 1.429 \\
\hline
\end{tabular}

Fonte: Tribunal Superior do Trabalho e Atlas do Desenvolvimento Humano.

Percebe-se que, com exceção da vara do trabalho de Estrela (RS), todas as unidades receberam uma média superior a 1.500 processos nos anos antecedentes à criação da segunda vara do trabalho, conforme recomenda a Resolução 63 do Conselho Superior da Justiça do Trabalho. Portanto, as varas do trabalho em municípios com o número de trabalhadores abaixo do valor de referência e que receberam uma nova unidade após a Resolução 63/2010 possuem uma média de recebimento de processos dentro do que foi estipulado pelo CSJT. Apenas o caso da vara de Estrela (RS) é destoante e precisa ser estudado em detalhes para entender os motivos do recebimento da segunda vara.

É necessário destacar que a própria Resolução 63/2010 dispõe que os critérios descritos acima podem ser relativizados quando as peculiaridades do caso concreto o exigirem, com vistas à interiorização da Justiça do Trabalho, garantia do acesso à justiça e ao imperativo da ampliação da cidadania, consoante o $\S 40$ do artigo 9. Por conseguinte, os casos de varas do trabalho criadas em municípios que estão próximos ou fora dos critérios estabelecidos pelo CSJT podem ser objeto de estudos de caso a fim de se analisar em profundidade as deliberações dos órgãos judiciais que propuseram e discutiram a criação das novas unidades. 


\section{Conclusão}

O objetivo da pesquisa foi verificar quais fatores são mais importantes para determinar os municípios que recebem varas judiciais. A expansão da Justiça do Trabalho foi usada como caso de estudo. A renda per capita e a taxa de frequência bruta ao ensino superior foram utilizadas para mensurar o nível socioeconômico das cidades brasileiras, enquanto a população economicamente ativa representou o critério estabelecido na Constituição Federal e na legislação específica. A distância para a capital do estado da federação, a distância para a vara do trabalho mais próxima, a estrutural judicial e o percentual de ocupados por setor da economia também fizeram parte da análise.

A população economicamente ativa apresentou alto poder explicativo no modelo estatístico realizado. O resultado aponta que o critério populacional estabelecido pela legislação foi respeitado na criação das varas do trabalho durante o intervalo temporal analisado. Em relação à renda per capita, os resultados foram diferentes do que se poderia esperar em face dos estudos anteriores dos aspectos territoriais do acesso à justiça nas varas estaduais. Ao manter as outras variáveis constantes, em 2003-2010 a renda per capita não influenciou o recebimento das unidades da Justiça do Trabalho.

Por outro lado, outros indicadores socioeconômicos inseridos no modelo foram relevantes para explicar o fenômeno. A proporção de indivíduos no ensino superior teve um efeito significativo, evidenciando que as localidades com, proporcionalmente, mais pessoas sendo formadas nas universidades foram mais beneficiadas na expansão da Justiça do Trabalho. O percentual de ocupados no setor de comércio também foi destaque como variável explicativa, quanto maior o número de trabalhadores empregados nesse setor, maior foi a chance de recebimento de varas do trabalho.

A estrutura judicial e a distância para a vara do trabalho mais próxima se mostraram importantes para a análise. Ao considerar todas as variáveis, os municípios mais distantes das unidades judiciárias já existentes foram mais contemplados com varas do trabalho. Ademais, quanto menos varas na localidade, maior foi a chance de o município receber uma unidade.

Em resumo, o modelo explicativo evidenciou um padrão diferente na expansão da Justiça do Trabalho em comparação às descrições apresentadas na literatura sobre a distribuição dos órgãos da Justiça Estadual. Primeiramente, o fator econômico mais relevante para o recebimento das varas parece ser um setor comercial mais robusto nos municípios, enquanto a renda per capita apresentou um efeito diferente do esperado. Além do mais, localidades mais distantes de onde existiam varas do trabalho foram mais contempladas na expansão. Por fim, destaca-se a relevância explicativa da população economicamente ativa.

Através da análise espacial, foram comparados os mapas com os municípios onde

foram criadas varas trabalhistas e o mapa do Índice de Desenvolvimento Humano Municipal. Não foi possível chegar a resultados conclusivos a respeito de algum padrão 
específico de concentração das varas nas localidades com maior desenvolvimento socioeconômico. Contudo, a distribuição regional das unidades demonstrou que a região Nordeste, em termos proporcionais, ficou abaixo da média das outras regiões.

As correlações entre as varas criadas na Lei n 10.770/2003 e o número de processos recebidos e julgados e o resíduo por Tribunal Regional do Trabalho demonstraram que a movimentação processual está relacionada com a criação das unidades judiciárias. Ao analisar as normas estabelecidas pelo Conselho Superior da Justiça do Trabalho na Resolução 63/2010 para que seja proposto o surgimento de uma nova vara, observou-se que, em regra, os critérios foram respeitados. Os municípios que apresentam padrões diferentes podem servir como objeto de estudo para uma análise em profundidade, como é o caso da criação da segunda vara do trabalho em Estrela (RS).

O objetivo deste artigo foi mensurar os efeitos de fatores socioeconômicos na criação das varas judiciais por meio de um desenho Large- $N$. Após a verificação do impacto das variáveis, torna-se necessária a busca pelas causas do efeito. A agenda de pesquisa na questão do acesso à justiça se dedicou de modo geral a apresentar os desequilíbrios na distribuição dos órgãos do Judiciário, porém pouco se avançou a respeito dos processos históricos que levaram à configuração atual. Em outras palavras, é preciso entender o "como" se deu o processo de criação de varas judiciais no Brasil. Para isso, precisamos de novas pesquisas com abordagem qualitativa, utilizando poucos casos, a fim de compreender o contexto no qual se produz o efeito observado.

Por fim, destacamos que o objetivo deste artigo não foi encontrar respostas definitivas para o problema apresentado, mas sim contribuir para o florescimento dos debates. É preciso, portanto, que os resultados sejam continuamente confrontados com novas análises, a fim de avançar em relação ao conhecimento já acumulado no campo.

\section{Referências bibliográficas}

ARANTES, R. B. Judiciário: entre a justiça e a política. In: AVELAR, L.; CintRA, A. O. (orgs.). Sistema político brasileiro: uma introdução. São Paulo: Editora Unesp, 2014.

AVRITZer, L.; MARonA, M.; Gomes, L. (orgs.). Cartografia da justiça no Brasil: uma análise a partir de atores e territórios. São Paulo: Saraiva, 2014.

BLACKSELL, M.; ECONOMIDES, K.; WATKINS, C. Justice outside the city: access to legal services in rural Britain. Essex: Longman Scientific and Technical, 1991.

BRASIL. Tribunal Superior do Trabalho. Resolução Administrativa $n^{\circ} 1407$, de 7 de junho de 2010. Diário Eletrônico da Justiça do Trabalho, Brasília, DF, $n^{\circ} 496,9$ jun. 2010. [Caderno do] Tribunal Superior do Trabalho, p. 18-28. Disponível em: <https://hdl.handle.net/20.500.12178/7113>. Acesso em: 10 set. 2016.

BRASIL. Secretaria de Reforma do Judiciário. Ministério da Justiça. Atlas de Acesso à Justiça: indicadores nacionais de acesso à justiça. Brasília: Ministério da Justiça, 2014. Disponível em: 
<http://www.acessoajustica.gov.br/pub/_downloads/caderno_inaj_2014.pdf>. Acesso em: 13 ago. 2016.

Cappelletti, M.; Garth, B. Acesso à justiça. Porto Alegre: Fabris, 1988.

CARDOSO, A. Direito do trabalho e relações de classe no Brasil contemporâneo. In: ViAnNA, L. W. (org.). A democracia e os três poderes no Brasil. Belo Horizonte: Editora da UFMG, 2002.

CARVALHo, E. "Revisão judicial e judicialização da política no direito ocidental: aspectos relevantes de sua gênese e desenvolvimento". Revista de Sociologia e Política, n² 28, p. 161-179, 2007.

Centro de Estudos da Metrópole. Limites territoriais do Brasil: regiões, estados e municípios. Bases cartográficas digitais georreferenciadas. 2013. Disponível em:

<http://web.fflch.usp.br/centrodametropole/upload/arquivos/Limites_Territoriais_do_Brasil_2013_C EM.rar>. Acesso em: 17 nov. 2016.

CORRÊA, L. R. A tessitura dos direitos: patrões e empregados na Justiça do Trabalho, 1953-1964. São Paulo: Editora LTr, 2011.

Delgado, M. G. Curso de direito do trabalho. São Paulo: Editora LTr, 2009.

Delgado, M. G.; Delgado, G. N. "Justiça do trabalho: 70 anos de justiça social". Revista do Tribunal Superior do Trabalho, vol. 77, n² 2, p. 103-115, 2011.

ECONOMIDES, K. Lendo as ondas do "Movimento de acesso à justiça": epistemologia versus metodologia? In: PANDolfI, D., et al. (orgs.). Cidadania, justiça e violência. Rio de Janeiro: Editora FGV, 1999.

FALCÃo, J. A. Cultura jurídica e democracia: a favor da democratização do Judiciário. In: LAMOUNIER, B.; WefForT, F.; BeneVIDES, M. V. (orgs.). Direito, cidadania e participação. São Paulo: Tao, 1981.

FEREJOHN, J. "Judicializing politics, politicizing law". Law and Contemporary Problems, vol. 65, $\mathrm{n}^{\circ}$ 3, p. $41-68,2002$.

JUnQUeIRA, E. B. "Acesso à justiça: um olhar retrospectivo". Revista Estudos Históricos, vol. 7, n 18, p. $1-15,1996$.

MARONA, M. "Acesso à qual justiça? A construção da cidadania brasileira para além da concepção liberal". Belo Horizonte. 247 f. Tese de Doutorado em Ciência Política. Universidade Federal de Minas Gerais, Belo Horizonte, 2013.

MenARD, S. "Applied logistic regression analysis". Sage Publications - Quantitative Applications in Social Sciences, vol. 7, n 106, p. 1-111, 2002.

Morel, R. L.; Pessanha, E. G. "Magistrados do trabalho no Brasil: entre a tradição e a mudança". Revista Estudos Históricos, n 37, p. 29-53, 2006.

"A Justiça do Trabalho". Tempo Social, vol. 19, n² 2, p. 87-109, 2007.

MourA, T., et al. Mapa da defensoria pública no Brasil. Brasília: Andep/Ipea, 2013.

OliveIRA, L. Sua excelência, o comissário e outros ensaios de sociologia jurídica. Rio de Janeiro: Letra Legal, 2004.

Oliveira Viana, F. Problemas do sindicalismo corporativo. Rio de Janeiro: Cia. Editora Nacional, 1936.

Pedroso, J.; TRINCÃo, C.; DiAS, J. P. "E a justiça aqui tão perto? As transformações no acesso ao direito e à justiça". Revista Crítica de Ciências Sociais, vol. 65, p. 77-106, 2003. 
AONDE CHEGA O JUDICIÁRIO? UMA AVALIAÇÃO DA EXPANSÃO DA JUSTIÇA DO TRABALHO NO BRASIL (2003-2010)

SADEK, M. T. "Poder Judiciário: perspectivas de reforma". Opinião Pública, vol. 10, n 1, p. 1-62, 2004.

"Acesso à justiça: um direito e seus obstáculos". Revista USP, n 101, p. 55-66, 2014.

SAdek, M. T. (org.). Acesso à justiça. São Paulo: Fundação Konrad Adenauer, 2001.

SAntos, B. S. A sociologia dos tribunais e a democratização da justiça. In: SAntos, B. S. Pela mão de Alice: o social e o político na pós-modernidade. Porto: Edições Afrontamento, 1999.

Santos, B. S.; Marques, M.; Pedroso, J. "Os tribunais nas sociedades contemporâneas". Revista Brasileira de Ciências Sociais, vol. 11, nº 30, p. 29-62, 1996.

SILVA, L. "A trajetória da Justiça do Trabalho". Revista do Tribunal Superior do Trabalho, vol. 77, $\mathrm{n}^{\circ}$ 2, p. 77-82, 2011.

Sinhoretto, J. A justiça perto do povo: reforma e gestão de conflitos. São Paulo: Alameda, 2011.

TAte, N.; VAllinder, T. (eds.). The global expansion of Judicial Power. New York: New York University Press, 1995.

ViannA, L. W. A judicialização da política e das relações sociais no Brasil. Rio de Janeiro: Revan, 1999.

WARAT, L. A. Senso comum teórico: as vozes incógnitas das verdades jurídicas. In: WARAT, L. A Introdução geral ao direito: a epistemologia jurídica da modernidade - Vol. 1. Porto Alegre: Safe, 1994. 


\begin{abstract}
How far does the judiciary go? An evaluation of Labor Justice expansion in Brazil (2003-2010)

This article tackles the following question: what factors determine the creation of Labor Courts in Brazil? According to constitutional criteria, population and judicial demand should guide the creation of judicial courts; however, the literature on access to justice claims that socioeconomic development could be the determinant. Considering that the expansion of the Labor Justice occurred in the last decades, it was possible to carry out a logistic regression model to test the effect of geographical, socioeconomic and demographic variables in the creation of units. The results indicate that the impact of the economically active population and the proportion of people in universities was relevant. Municipalities more distant from the existing judicial units and with fewer units in operation were taken into greater consideration in the expansion of the Labor Justice.
\end{abstract}

Keywords: Labor Justice; judiciary; access to justice; judicial units; municipalities

\title{
Resumen
}

¿Dónde está la justicia? Una evaluación de la expansión de la Justicia Laboral en Brasil (2003-2010)

¿Qué factores determinan la creación de unidades de Justicia Laboral en Brasil? Es el problema en esta investigación. De acuerdo con los criterios constitucionales, la población y la demanda de poder judicial deberían guiar la creación de unidades de justicia. Sin embargo, la literatura que estudia el acceso a la justicia indica la posibilidad de que sea el desarrollo socio-económico el factor determinante para su surgimiento. Considerando que la expansión de la Justicia Laboral ocurrió en las últimas décadas, fue posible realizar un modelo de regresión logística para medir el efecto de variables geográficas, socioeconómicas y demográficas en la creación de las unidades. Los resultados demostraron que el impacto de la población económicamente activa y de la proporción de personas que cursan la enseñanza superior por municipio fue relevante. Los municipios más distantes de las unidades ya existentes y con menos unidades en funcionamiento también fueron más beneficiados con la expansión de la Justicia Laboral.

Palabras clave: Justicia Laboral; poder judicial; acceso a justicia; unidades de justicia; municipios

\section{Résumé}

Où est la justice? Une évaluation de La Justice du Travail au Brésil (2003-2010)

Quels facteurs déterminent la création de tribunaux du travail au Brésil? C'est le problème que se pose notre recherche. Selon les critères constitutionnels, la population et la demande de pouvoir judiciaire devraient guider la création de juridictions judiciaires. Cependant, la littérature qui étudie l'accès à la justice indique que le développement socio-économique est peut-être le facteur déterminant de cette apparition. Si I'on prend en compte que l'expansion de la Justice du Travail a eu lieu surtout au cours des dernières décennies, il a été possible de réaliser un modèle de régression logistique pour tester l'effet des variables géographiques, socioéconomiques et démographiques dans la création d'unités. Les résultats ont montré que l'impact de la population économiquement active et de la proportion de personnes fréquentant l'enseignement supérieur dans la municipalité était pertinent. Les municipalités les plus éloignées des juridictions existantes et avec moins d'unités en fonctionnement ont également bénéficié davantage de l'expansion de la Justice du Travail.

Mots-clés: Justice du Travail; pouvoir judiciaire; accès à la justice; tribunaux judiciaires; municipalités

Artigo submetido à publicação em 5 de abril de 2017. Versão final aprovada em 26 de junho de 2018.

Opinião Pública adota a licença Creative Commons CC-BY. 